\title{
Prognostic factors after complete resection of pN2 non-small cell lung cancer
}

\author{
Makoto Sonobe, MD, PhD, ${ }^{a}$ Hiroshi Date, $\mathrm{MD}, \mathrm{PhD},{ }^{\mathrm{a}}$ Hiromi Wada, $\mathrm{MD}, \mathrm{PhD},{ }^{\mathrm{a}, \mathrm{b}}$ \\ Kenichi Okubo, MD, PhD, ${ }^{\mathrm{a}, \mathrm{c}}$ Hiroshi Hamakawa, MD, PhD, ${ }^{\mathrm{a}, \mathrm{d}}$ Satoshi Teramukai, PhD, \\ Akihide Matsumura, MD, PhD, ${ }^{\mathrm{f}}$ Tatuo Nakagawa, MD, PhD,${ }^{\mathrm{g}}$ Shin-ichi Sumitomo, MD, PhD, ${ }^{\mathrm{h}}$ \\ Yoshihiro Miyamoto, MD, PhD, ${ }^{\mathrm{i}}$ Norihito Okumura, MD, PhD, ${ }^{\mathrm{j}}$ Sadanori Takeo, MD, PhD, ${ }^{\mathrm{k}}$ \\ Kenzo Kawakami, MD, PhD, ${ }^{1}$ Minoru Aoki, MD, PhD, ${ }^{\mathrm{m}}$ and Shinji Kosaka, MD, PhD, ${ }^{n}$ \\ The Japan-Multinational Trial Organization
}

Objectives: This retrospective, multicenter study aimed to determine prognostic factors of completely resected pathologic N2 stage IIIA non-small cell cancer (NSCLC).

\begin{abstract}
Methods: From 25 participating hospitals, 496 patients ( 325 men and 171 women; median age, 65 years) who underwent complete resection without preoperative treatment for pT1-3 N2 M0, stage IIIA NSCLC between 2000 and 2004 were enrolled. Lobectomy/bilobectomy was performed in 462 patients and pneumonectomy in 34. Some kind of adjuvant chemotherapy was administered to 296 patients. Survivals were calculated using the Kaplan-Meier method, and prognostic factors were determined using the Cox proportional hazards model.
\end{abstract}

Results: Five-year overall survival (OS) and disease-free survival (DFS) were $44.8 \%$ and $24.2 \%$, respectively. pT classification (hazard ratio (HR), pT1/pT2/pT3 $=1 / 1.32 / 2.03$ ), single or multiple N2 metastases (HR, single/ multiple $=1 / 1.36$ ), and skip or nonskip N2 metastasis (HR, skip/nonskip $=1 / 1.30)$ were found to be independent prognostic factors for DFS. Sex (HR, female/male = 1/1.36), performance status (HR, PS-0/PS-1 = 1/1.37), tumor diameter (HR, 1.12 per $1-\mathrm{cm}$ increase), pT-factor $(\mathrm{HR}, \mathrm{pT} 1 / \mathrm{pT} 2 / \mathrm{pT} 3=1 / 1.37 / 2.22)$, and extent of N2 metastasis $(\mathrm{HR}$, localized/extended $=1 / 1.39)$ were shown to be independent prognostic factors for OS.

Conclusions: We found that pT classification was a significant prognostic indicator for OS and DFS whereas tumor diameter, performance status, and sex were ones for OS. Single N2 metastasis and skip N2 metastasis were demonstrated as favorable prognostic factors for DFS, limited N2 metastasis was one for OS, and these should be considered as stratification factors for trial on adjuvant therapy. (J Thorac Cardiovasc Surg 2013;146:788-95)

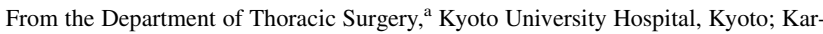
asuma Wada Clinic, ${ }^{\mathrm{b}}$ Kyoto; Department of Thoracic Surgery, ${ }^{\mathrm{c}}$ Tokyo Medical and Dental University Hospital, Tokyo; Department of Thoracic Surgery, ${ }^{\mathrm{d}}$ Kobe City Medical Center General Hospital, Kobe; Department of Clinical Trial Design and Management, ${ }^{\mathrm{e}}$ Translational Research Center, Kyoto University Hospital, Kyoto; Department of Thoracic Surgery, ${ }^{\mathrm{f}}$ National Hospital Organization Kinki-Chuo Chest Medical Center, Sakai; Department of Thoracic Surgery, ${ }^{\mathrm{g}}$ Tenri Hospital, Tenri; Department of Thoracic Surgery, ${ }^{\mathrm{h}}$ Japanese Red Cross Society, Wakayama Medical Center, Wakayama; Department of Thoracic Surgery, National Hospital Organization Himeji Medical Center, Himeji; Department of Thoracic Surgery, ${ }^{\mathrm{j}}$ Kurashiki Central Hospital, Kurashiki; Department of Thoracic Surgery, ${ }^{\mathrm{k}}$ National Hospital Organization Kyushu Medical Center, Fukuoka; Department of Thoracic Surgery, ${ }^{1}$ Shiga Medical Center for Adults, Moriyama; Department of Thoracic Surgery, ${ }^{\mathrm{m}}$ Nishi-Kobe Medical Center, Kobe; and Department of Thoracic Surgery, ${ }^{\mathrm{n}}$ Shimane Prefectural Central Hospital, Izumo, Japan.

The study was supported by an incorporated nonprofit organization, The JapanMultinational Trial Organization (Nagoya, Japan).

Disclosures: Authors have nothing to disclose with regard to commercial support.

Received for publication Nov 19, 2012; revisions received April 17, 2013; accepted for publication April 25, 2013; available ahead of print July 1, 2013.

Address for reprints: Hiroshi Date, MD, PhD, Department of Thoracic Surgery, Kyoto University Hospital, Shogoin-Kawara-cho 54, Sakyo-ku, Kyoto 606-8507, Japan (E-mail: hdate@kuhp.kyoto-u.ac.jp).

0022-5223/\$36.00

Copyright (C) 2013 by The American Association for Thoracic Surgery

http://dx.doi.org/10.1016/j.jtcvs.2013.04.043
}

The prognosis of completely resected pathologic (p) N2 stage IIIA non-small cell lung cancer (NSCLC) is still unsatisfactory owing to a high incidence of metastasis or tumor recurrence. ${ }^{1}$ A meta-analysis on cisplatin-based adjuvant chemotherapy after initial resection has shown that it improves survival. ${ }^{2}$ However, the efficacy of adjuvant chemotherapy in Japanese phase III trials has been controversial. ${ }^{3,4}$ Therefore, several phase II and III trials on adjuvant chemotherapy have been planned in Japan.

It is widely known that the prognosis of pN2 stage IIIA NSCLC is heterogeneous, and T and clinical (c) N classifications have been identified as prognostic factors. ${ }^{5}$ These factors are considered as stratification criteria in clinical trials. Although pattern of metastasis to N2 regions has also been reported as a prognostic factor. ${ }^{5,6}$ Its influence on adjuvant chemotherapy has not yet been clarified; thus, it is not considered as stratification criteria in clinical trials of adjuvant chemotherapy for patients with $\mathrm{pN} 2$ stage IIIA NSCLC.

In this study, we retrospectively investigated the outcome of patients with completely resected pN2 stage IIIA NSCLC, who were treated at institutions participating in 


$$
\begin{aligned}
& \text { Abbreviations and Acronyms } \\
& \begin{aligned}
\text { c } & =\text { clinical } \\
\text { DFS } & =\text { disease-free survival } \\
\text { ECOG } & =\text { Eastern Cooperative Oncology Group } \\
\text { EGFR } & =\text { epidermal growth factor receptor } \\
\text { HR } & =\text { hazard ratio } \\
\text { IV-CT } & =\text { intravenous chemotherapy } \\
\text { JMTO } & =\text { Japan-Multinational Trial Organization } \\
\text { NSCLC } & =\text { non-small cell lung cancer } \\
\text { OS } & =\text { operative survival } \\
\text { p } & =\text { pathologic } \\
\text { PS } & =\text { performance status } \\
\text { UFT } & =\text { tegafur-uracil }
\end{aligned}
\end{aligned}
$$

the clinical trial group Japan-Multinational Trial Organization (JMTO) to determine prognostic factors, particularly prognostic value of pattern of metastasis to $\mathrm{N} 2$ regions and adjuvant chemotherapy.

\section{PATIENTS AND METHODS \\ Study Design}

In this retrospective study, 25 institutions affiliated with the JMTO (listed in the Acknowledgements section) recruited patients who met the eligibility criteria, which began in January 2008, and all data including follow-up information until either death or December 2010 were assessed in April 2011.

\section{Eligibility Criteria}

Patients with NSCLC who had undergone complete resection by lobectomy, bilobectomy, or pneumonectomy with at least standard ipsilateral hilar/mediastinal lymph node dissection (defined by the General Rule for Clinical and Pathological Record of Lung Cancer $^{7}$ ) between January 2000 and December 2004, and whose tumors were pathologically proven T1-3 N2 M0, stage IIIA according to the sixth edition of the International System for Staging Lung Cancer, ${ }^{8}$ were eligible. The eligibility criteria included the following: no chemotherapy or radiotherapy before surgery; older than 20 years of age; Eastern Cooperative Oncology Group (ECOG) performance status (PS) of 0 or 1; and written informed consent for surgical resection. Patients were excluded if they had 1 or more of the following factors: active double cancer; serious infections; cardiac, hepatic, renal, or psychologic diseases at the time of lung resection; history of preoperative treatment with chemotherapy or radiotherapy; and intraoperative anticancer drug administration in the thorax or pericardium. Patients who underwent sublobar resection such as segmentectomy for their NSCLC were also excluded. The study protocol was approved by the ethics committee of JMTO (JMTO LC 05-01 study) and the institutional ethics committee of each participating institution. From 25 institutions, 512 patients were recruited. Of these, 12 patients received sublobar resection and 4 patients received insufficient lymph node dissection. Finally, 496 patients were eligible in the study (Figure 1). Their characteristics are shown in Table 1 . Of these, $2(0.4 \%)$ patients died of postoperative complication within 30 days after surgery.

\section{Adjuvant Therapy and Follow-up}

In the period between January 2000 and December 2004, the significance of induction treatment, adjuvant chemotherapy, or adjuvant radiotherapy was not established. Therefore, indications for resection for $\mathrm{cN} 2$ disease and postoperative chemotherapy and/or radiotherapy were dependent on each institution. As adjuvant chemotherapy, oral tegafur-uracil (UFT) or intravenous chemotherapy (IV-CT) was selected. IV-CT regimens that were used included carboplatin and paclitaxel, cisplatin and docetaxel, cisplatin or carboplatin and gemcitabine, cisplatin and 5-fluorouracil, and a combination of cisplatin, mitomycin $\mathrm{C}$, and vindesine. As adjuvant radiotherapy, irradiation with 50 to $60 \mathrm{~Gy}$ to hilar and mediastinal areas was performed. Of 496 patients, $122(24.6 \%)$ received IV-CT, $89(17.9 \%)$ received IV-CT and radiotherapy, $60(12.1 \%)$ received UFT, $25(5.0 \%)$ received UFT and radiotherapy, $49(9.9 \%)$ received radiotherapy, and 151 $(30.4 \%)$ did not receive adjuvant therapy.

The follow-up examination schedule was arranged by each individual institution; most of the patients received medical check-ups and chest $\mathrm{x}$-ray films at least twice per year.

\section{Data Collection}

The collected data included age, sex, ECOG PS, cT and cN classifications, affected lobe of lung, operation date, operation mode, $\mathrm{pT}$ classification, maximum tumor size (centimeters), tumor histology in accordance with the World Health Organization classification, ${ }^{9}$ station of node(s) with metastasis, adjuvant chemotherapy, adjuvant radiation therapy, presence or absence of recurrent tumor, date of diagnosis of recurrent tumor, and follow-up information until either death or December 2010. These data were obtained from the inpatient and outpatient medical records and imaging tests. These data were accumulated through a web-based registration system established by JMTO.

\section{Patterns of Metastasis to N2 Regions}

Metastasis to the N2 regions was classified as follows: (1) single (metastasis to $1 \mathrm{~N} 2$ station) or multiple (metastases to 2 or more N2 stations) N2 metastases; (2) skip (no metastasis to the N1 region) or nonskip (metastasis to the N1 region) N2 metastases; and (3) extent of N2 stations with metastasis, defined as localized or extended N2 metastasis. "Localized N2 metastasis" was defined as metastatic spread of the tumor to right \#1, right $\# 2$, \#3, and/or right \#4 N2 station(s) of the right upper lobe; left \#1, left $\# 2$, \#3, left \#4, \#5, and/or \#6 N2 station(s) of the left upper lobe; right $\# 1$, right \#2, \#3, right \#4, and/or \#7 N2 station(s) of the right middle lobe; \#7, right \#8, and/or right \#9 N2 station(s) of the right lower lobe, and \#7, left \#8, and/or left \#9 N2 station(s) of the left lower lobe. "Extended N2 metastasis" was defined as metastasic spread of the tumor to \#7, ipsilateral \#8, and/or ipsilateral \#9 N2 station(s) of the upper lobe; right \#8 and/or right \#9 $\mathrm{N} 2$ station(s) in the right middle lobe; ipsilateral \#1, \#2, \#3, and/or \#4 N2 station(s) in the right lower lobe; and ipsilateral \#1, \#2, \#3, \#4, \#5, and/or \#6 N2 station(s) in the left lower lobe. Under these classifications, $294(59.3 \%)$ patients had single N2 metastasis and 202 $(40.7 \%)$ had multiple N2 metastasis. An equal frequency of skip and nonskip N2 metastases was observed; both were found in $248(50.0 \%)$ patients. The number of patients with skip N2 metastasis by primary tumor location was $89(50.3 \%)$ of 177 in the right upper lobe, $10(40.0 \%)$ of 25 in the right middle lobe, $57(47.5 \%)$ of 120 in the right lower lobe, $63(57.3 \%)$ of 110 in the left upper lobe, and $29(45.3 \%)$ of 64 in the left lower lobe. Localized N2 metastases were observed in 369 (74.4\%) patients, and extended N2 metastases were in 127 (25.6\%) patients. The number of patients with extended N2 metastasis by primary tumor location was $34(19.2 \%)$ of 177 in the right upper lobe, $0(0 \%)$ of 25 in the right middle lobe, $50(41.7 \%)$ of 120 in the right lower lobe, $14(12.7 \%)$ of 110 in the left upper lobe, and $29(45.3 \%)$ of 64 in left lower lobe.

\section{Statistical Considerations}

Categorical data were examined using the $\chi^{2}$ test. Prognostic evaluation was performed by consideration of the disease-free survival (DFS) and overall survival (OS). DFS was defined as time to lung cancer recurrence or non-lung cancer death. The impact of the following clinical-pathologic 


\section{2 patients with completely resected pathologically T1-3N2M0, stage IIIA non-small cell lung cancer between $1 / 1 / 2001$ and $12 / 31 / 2004$, from 25 participating institutes.}

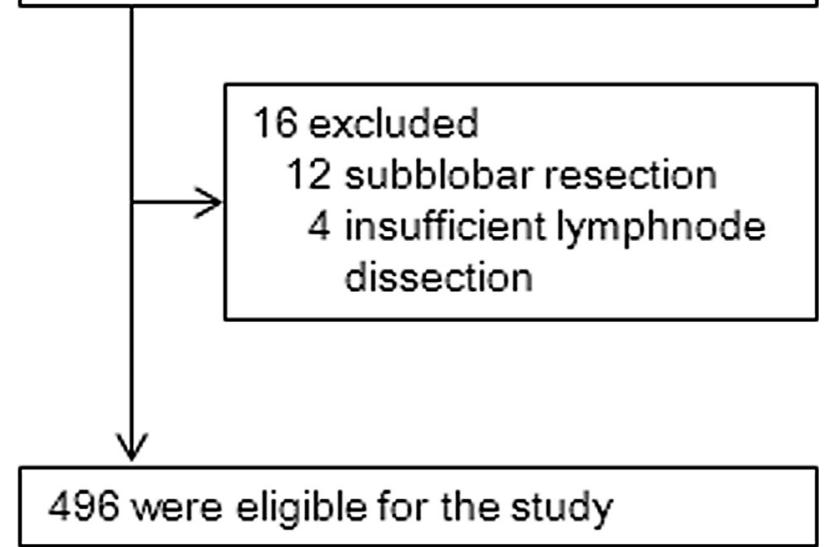

FIGURE 1. Patient selection. From 25 institutions, 512 patients who potentially met the study criteria were recruited. Assessment of collected data revealed that 12 patients received sublobar resection and 4 patients received insufficient lymph node dissection. Finally, 496 patients were eligible in the study.

factors on DFS and OS was evaluated: age ( $\leq 60,61-70$, or $>70$ years of age), sex, ECOG PS (PS 0 vs PS 1), tumor size in maximal diameter (centimeters), cT classification, $\mathrm{cN}$ classification, tumor location (right vs left), operation mode (pneumonectomy vs lobectomy including bilobectomy and sleeve lobectomy), tumor histology (adenocarcinoma, squamous cell carcinoma, large cell carcinoma, or adenosquamous cell carcinoma), pT classification, adjuvant chemotherapy (none, UFT, or IV-CT for simplification purposes inasmuch as a wide range of intravenous chemotherapy regimens were used), adjuvant radiation therapy, single or multiple N2 metastases, skip or nonskip N2 metastasis, and localized or extended N2 metastasis. Survival curves were calculated using the Kaplan-Meier method and compared using the log-rank test. To evaluate the prognostic effect of IV-CT compared with surgery alone, we matched patients on the basis of propensity score. The propensity score for IV-CT was constructed using binary logistic regression including patients' age, sex, ECOG PS, tumor histology, pT classification, operation mode, single or multiple N2 metastases, skip or nonskip N2 metastasis, and localized or extended N2 metastasis. Nearest neighbor matching with a caliper of .005 difference was used to match 128 patients with IV-CT and 128 patients without no adjuvant chemotherapy. Regarding pT classification and pattern of metastasis to N2 region, 5-year DFSs on the basis of IV-CT and radiotherapy were calculated. When significant $(P$ value $<.05)$ and borderline $(P$ value $<.10)$ variables under this univariate method showed linearity and time dependency, they were tested with a multivariate analysis using the Cox proportional hazards model. JMP software version 9.03 (SAS Institute, Inc, Cary, NC) was used to carry out all statistical calculations. All statistical tests were 2-sided. Our statistician (S.T.) reviewed the statistical methods.

\section{RESULTS}

\section{Survival Analyses}

The median follow-up period was 57 months. Recurrence occurred in 342 patients during the follow-up period, and of
TABLE 1. Patient characteristics

\begin{tabular}{|c|c|}
\hline Variables & No. of patients $(\%)$ \\
\hline Age (y) & Mean 65.0 \\
\hline$\leq 60$ & $152(30.6 \%)$ \\
\hline $61-70$ & $175(35.3 \%)$ \\
\hline$>71$ & $169(34.1 \%)$ \\
\hline \multicolumn{2}{|l|}{ Sex } \\
\hline Female & $171(34.5 \%)$ \\
\hline Male & $325(65.5 \%)$ \\
\hline \multicolumn{2}{|l|}{ ECOG performance status } \\
\hline PS 0 & $404(81.5 \%)$ \\
\hline PS 1 & $92(18.5 \%)$ \\
\hline \multicolumn{2}{|l|}{ Clinical $\mathrm{T}$ classification } \\
\hline cT1 & $204(41.1 \%)$ \\
\hline $\mathrm{cT} 2$ & $251(50.6 \%)$ \\
\hline $\mathrm{cT} 3 / 4$ & $41(8.3 \%)$ \\
\hline \multicolumn{2}{|l|}{ Clinical $\mathrm{N}$ classification } \\
\hline cNO & $311(62.7 \%)$ \\
\hline $\mathrm{cN} 1$ & $62(12.5 \%)$ \\
\hline $\mathrm{cN} 2 / 3$ & $123(24.8 \%)$ \\
\hline \multicolumn{2}{|l|}{ Clinical stage } \\
\hline Stage I & $295(59.5 \%)$ \\
\hline Stage II & $69(13.9 \%)$ \\
\hline Stage III & $132(26.6 \%)$ \\
\hline \multicolumn{2}{|l|}{ Tumor location } \\
\hline Right & $322(64.9 \%)$ \\
\hline Left & $174(35.1 \%)$ \\
\hline \multicolumn{2}{|l|}{ Types of resection } \\
\hline Lobectomy & $448(90.3 \%)$ \\
\hline Sleeve lobectomy & $12(2.4 \%)$ \\
\hline Bilobectomy & $2(0.4 \%)$ \\
\hline Pneumonectomy & $34(6.9 \%)$ \\
\hline \multicolumn{2}{|l|}{ Pathologic $\mathrm{T}$ classification } \\
\hline pT1 & $191(38.5 \%)$ \\
\hline pT2 & $256(51.6 \%)$ \\
\hline pT3 & $49(9.9 \%)$ \\
\hline \multicolumn{2}{|l|}{ Tumor histology } \\
\hline Adenocarcinoma & $357(72.0 \%)$ \\
\hline Squamous cell carcinoma & $110(22.2 \%)$ \\
\hline Large cell carcinoma & $17(3.4 \%)$ \\
\hline Adenosquamous cell carcinoma & $12(2.4 \%)$ \\
\hline \multicolumn{2}{|l|}{ Adjuvant therapy } \\
\hline None & $151(30.4 \%)$ \\
\hline Intravenous chemotherapy & $122(24.6 \%)$ \\
\hline Intravenous chemotherapy + radiation & $89(17.9 \%)$ \\
\hline Oral tegafur and uracil & $60(12.1 \%)$ \\
\hline Oral tegafur and uracil + radiotherapy & $25(5.0 \%)$ \\
\hline Radiotherapy & $49(9.9 \%)$ \\
\hline
\end{tabular}

these, 253 patients died of recurrent tumors whereas 89 patients were alive with recurrent tumors. Treatments after recurrence were given according to each institutional protocol. Thirty-six patients died of non-lung cancer-related causes, and 118 patients were alive without tumor recurrence. The 3- and 5-year OSs were 59.5\% and $44.8 \%$, 
TABLE 2. Univariate analyses of prognostic factors for OS and DFS

\begin{tabular}{|c|c|c|c|c|c|c|c|}
\hline Factors & Variables & Five-year OS (\%) & & $P$ value & Five-year DFS (\%) & & $P$ value \\
\hline \multirow[t]{3}{*}{ Age } & $\leq 60$ & 46.2 & ] & & 22.6 & 7 & \\
\hline & $61-70$ & 50.2 & \} & .9377 & 25.1 & \} & .8889 \\
\hline & $>71$ & 37.5 & \} & .0329 & 24.8 & \} & .6914 \\
\hline \multirow[t]{2}{*}{ Sex } & Female & 53.8 & & & 24.1 & & \\
\hline & Male & 40.1 & & .0081 & 24.3 & & 6939 \\
\hline \multirow[t]{2}{*}{ ECOG performance status } & PS 0 & 47.1 & & & 25.5 & & \\
\hline & PS 1 & 34.1 & & .0061 & 18.1 & & .1823 \\
\hline Maximum tumor diameter & By $1 \mathrm{~cm}$ increase & - & & $<.0001$ & - & & .0001 \\
\hline \multirow[t]{3}{*}{ Clinical T classification } & $\mathrm{cT} 1$ & 54.2 & ]) & & 29.8 & $7)$ & \\
\hline & $\mathrm{cT} 2$ & 41.1 & \} & .0019 & 21.6 & \} & .0370 \\
\hline & $\mathrm{cT} 3 / 4$ & 21.6 & \} & $<.0001$ & 12.7 & \} & .0006 \\
\hline \multirow[t]{3}{*}{ Clinical $\mathrm{N}$ classification } & $\mathrm{cNO}$ & 48.7 & $7)$ & & 25.2 & $7)$ & \\
\hline & $\mathrm{cN} 1$ & 41.3 & \} & .2275 & 23.8 & \} & .6084 \\
\hline & $\mathrm{cN} 2 / 3$ & 36.6 & \} & .0095 & 22.1 & \} & .2978 \\
\hline \multirow[t]{2}{*}{ Tumor location } & Right & 42.3 & & & 24.0 & & \\
\hline & Left & 49.2 & & .2125 & 24.6 & & .6077 \\
\hline \multirow[t]{2}{*}{ Types of resection } & Lobectomy* & 46.5 & & & 25.2 & & \\
\hline & Pneumonectomy & 20.1 & & .0011 & 11.8 & & .0142 \\
\hline \multirow[t]{3}{*}{ Pathologic $\mathrm{T}$ classification } & pT1 & 58.3 & 7 & & 33.1 & $7]$ & \\
\hline & pT2 & 40.3 & \} & $<.0001$ & 20.1 & \} & .0016 \\
\hline & pT3 & 14.1 & \} & $<.0001$ & 11.1 & \} & $<.0001$ \\
\hline \multirow[t]{4}{*}{ Tumor histology } & Adenocarcinoma & 58.3 & $1)$ & & 21.8 & ) & \\
\hline & Squamous cell ca. & 42.4 & & .1587 & 30.3 & & .4844 \\
\hline & Large cell ca. & 35.3 & \} & .4026 & 29.4 & \} & .7746 \\
\hline & Adenosquamous cell ca. & 46.7 & \} & .9827 & 33.3 & \} & .8825 \\
\hline \multirow[t]{3}{*}{ Adjuvant chemotherapy } & None & 41.0 & 7) & & 22.2 & 7) & \\
\hline & Intravenous chemotherapy & 46.9 & \} & .0743 & 26.6 & \} & .0497 \\
\hline & Oral tegafur and uracil & 48.2 & \} & .1124 & 23.3 & \} & .4579 \\
\hline \multirow[t]{2}{*}{ Adjuvant radiotherapy } & None & 45.0 & & & 26.5 & & \\
\hline & Mediastinal irradiation & 44.3 & & .9041 & 19.6 & & .3846 \\
\hline \multirow[t]{2}{*}{ Single or multiple N2 metastases } & Single & 49.4 & & & 30.9 & & \\
\hline & Multiple & 38.6 & & .0291 & 14.8 & & .0002 \\
\hline \multirow[t]{2}{*}{ Skip N2 metastasis } & Skip & 47.8 & & & 29.4 & & \\
\hline & Nonskip & 41.7 & & .1680 & 19.0 & & .0071 \\
\hline \multirow[t]{2}{*}{ Extent of $\mathrm{N} 2$ metastasis } & Localized & 48.6 & & & 27.5 & & \\
\hline & Extended & 34.1 & & .0047 & 14.9 & & .0074 \\
\hline
\end{tabular}

OS, Overall survival; DFS, disease-free survival; ECOG, Eastern Cooperative Oncology Group; ca, carcinoma; PS, performance status. *Lobectomy included lobectomy, bilobectomy, and lobectomy with bronchoplasty.

respectively, and the 3- and 5-year DFSs were $31.1 \%$ and $24.2 \%$, respectively.

Univariate analysis for OS indicated that increased age, male sex, ECOG PS 1, increasing cT classification, increasing $\mathrm{cN}$ classification, pneumonectomy, increasing maximum tumor diameter, increasing pT classification, multiple N2 metastases, and extended N2 metastasis were significantly associated with poor OS (Table 2). Univariate analysis also revealed that increasing cT classification, pneumonectomy, increasing maximum tumor diameter, increasing pT classification, multiple N2 metastases, nonskip N2 metastasis, and extended N2 metastasis were significantly associated with poor DFS (Table 2, Figure 2, $A$ and $B)$. IV-CT had a marginal prognostic advantage on OS and DFS as compared with no adjuvant chemotherapy although UFT or adjuvant radiotherapy did not (Table 2). In the IV-CT group $(\mathrm{n}=211)$, 5-year OS and DFS of patients with radiotherapy $(n=89)$ were $44.8 \%$ and $22.1 \%$, respectively, and were not different from 5-year OS $(48.4 \%)$ and DFS $(29.7 \%)$ of those without radiotherapy $(\mathrm{n}=122)$. In 128 matched pairs of patients by propensity score, however, IV-CT had no prognostic advantage on OS and DFS (Figure 2, $C$ and $D$ ).

By multivariate analysis, sex, ECOG PS, maximum tumor diameter, $\mathrm{pT}$ classification, and extent of $\mathrm{N} 2$ metastasis were revealed to be independent prognostic factors affecting OS (Table 3). Meanwhile, pT classification, single or multiple N2 metastases, and skip or nonskip N2 metastasis were demonstrated to be important prognostic factors for DFS (Table 3). 

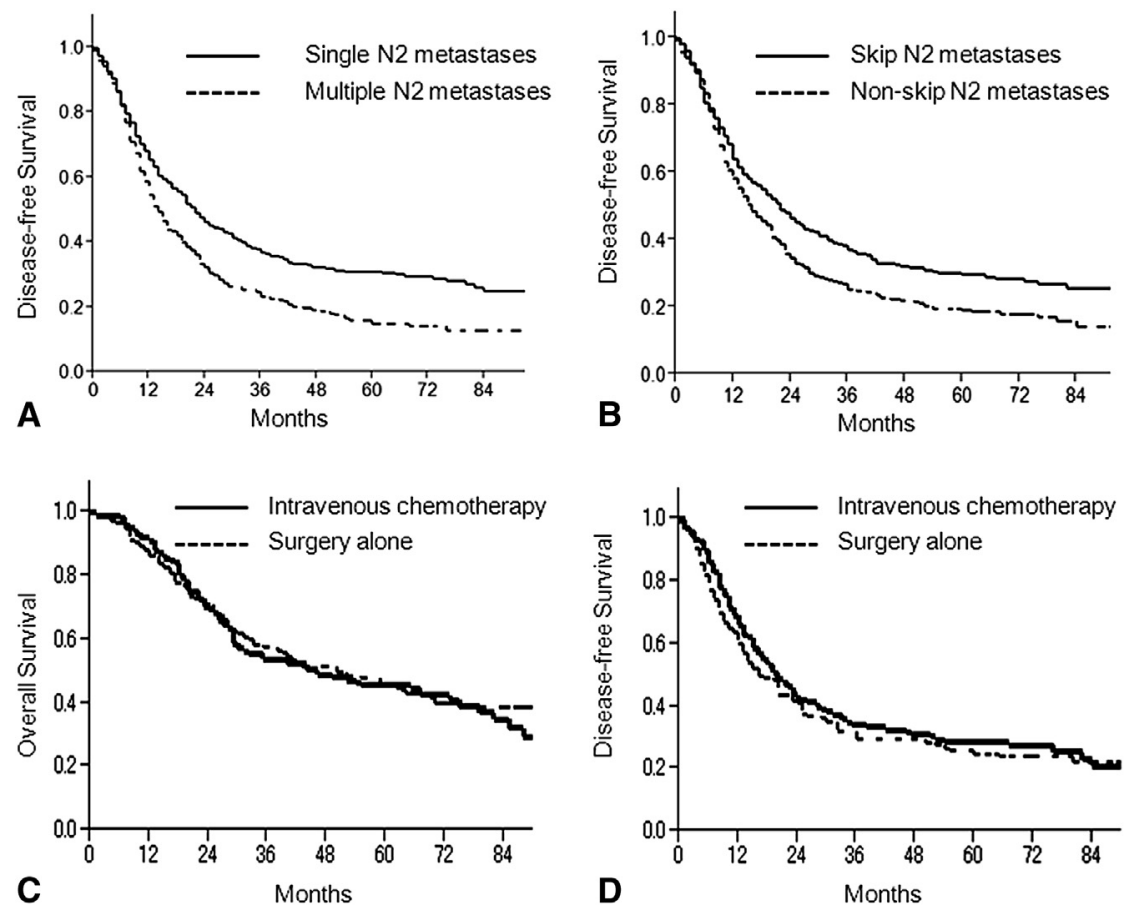

FIGURE 2. A, Disease-free survival according to single or multiple N2 metastases. Disease-free survival was significantly better in the single N2 metastasis group than in the multiple N2 metastases group $(P=.0002$, log-rank test). B, Disease-free survival according to skip or nonskip N2 metastasis. Diseasefree survival was significantly better in the skip N2 metastasis group than in the nonskip N2 metastasis group $(P=.0071, \log$-rank test $)$. C, Propensity scoreadjusted overall survival according to intravenous chemotherapy. There was no difference between the intravenous chemotherapy group and surgery alone group $(P=.4583, \log$-rank test $)$. D, Propensity score-adjusted disease-free survival according to intravenous chemotherapy. There was no difference between the intravenous chemotherapy group and surgery alone group $(P=.8611, \log$-rank test).

\section{Adjuvant Chemotherapy by pT Classification and Pattern of Metastasis to N2 Regions}

Because only IV-CT had a potential prognostic advantage, survival of patients with IV-CT $(\mathrm{n}=122)$ or IV-CT and radiotherapy $(\mathrm{n}=89)$ was compared with that of those with surgery alone $(n=151)$ according to $\mathrm{pT}$ classification and pattern of metastasis to N2 regions. There were no differences of DFS and OS among IV-CT, IV-CT and radiation, and no adjuvant therapy groups according to $\mathrm{pT}$ classification, single or multiple N2 metastases, or extent of N2 stations with metastasis. In the skip N2 metastasis group, 5-year DFSs were $44.9 \%$ in patients receiving IV-CT $(\mathrm{n}=49), 28.7 \%$ in patients receiving IV-CT and radiotherapy $(\mathrm{n}=46)$, and $26.1 \%$ in patients without adjuvant therapy $(\mathrm{n}=68)$, and an effect of IV-CT on DFS was observed $(P=.0167, \log$-rank test). However, in the nonskip N2 metastasis group, 5-year DFSs were $19.3 \%$ in patients receiving IV-CT $(\mathrm{n}=79), 15.5 \%$ in patients receiving IV-CT and radiotherapy $(n=43)$, and $21.8 \%$ in patients without adjuvant therapy $(\mathrm{n}=72)$, with no observed differences among them $(P=.9970, \log$-rank test). The percentage of patients receiving adjuvant IV-CT or IV-CT and radiotherapy was not different among the pT classification groups $\left(P=.5071, \chi^{2}\right.$ test $)$ and not different between single N2 metastasis and multiple N2 metastases groups $(P=.5312$, $\chi^{2}$ test), skip or nonskip $\mathrm{N} 2$ metastasis $\left(P=.2344, \chi^{2}\right.$ test), or extent of $\mathrm{N} 2$ stations with metastasis $(P=.1184$, $\chi^{2}$ test).

\section{DISCUSSION}

The 5-year OS in the study was $44.8 \%$ and was higher than that reported by Goldstraw and associates ${ }^{10}(24 \%)$ under a median follow-up period of 57 months. In our cohort, 89 patients were alive at the end of the study (December 2010), and they provided a higher OS than DFS. This may be due to the exclusion of patients with comorbidity, successful treatment for recurrent diseases including chemotherapy, radiotherapy, and/or molecular targeting drugs, ${ }^{11}$ and high percentage of tumors with mutations in the epidermal growth factor receptor (EGFR) gene in Japan, ${ }^{12-14}$ which could be a better prognostic factor after recurrence. ${ }^{14}$

We found that $\mathrm{pT}$ classification was a strong independent prognostic factor for OS and DFS in patients with completely resected $\mathrm{pN} 2$ stage IIIA NSCLC. Increased pT classification signifies enhanced tumor invasiveness and/or tumor burden. Several studies in Japan also showed a prognostic significance of $\mathrm{pT}$ classification in cases of completely resected pN2 NSCLC, ${ }^{5,6,15}$ and our findings are highly corroborative with theirs. 
TABLE 3. Multivariate analyses of prognostic factors for OS and DFS

\begin{tabular}{|c|c|c|c|}
\hline Factors for overall survival & Variables & Hazard ratio $(95 \%$ CI $)$ & $P$ value \\
\hline \multirow[t]{3}{*}{ Age } & $\leq 60$ & 1 & \\
\hline & $61-70$ & $0.86(0.63-1.18)$ & .3401 \\
\hline & $>71$ & $1.19(0.87-1.62)$ & .2760 \\
\hline \multirow[t]{2}{*}{ Sex } & Female & 1 & \\
\hline & Male & $1.35(1.05-1.75)$ & .0190 \\
\hline \multirow[t]{2}{*}{ ECOG Performance status } & PS 0 & 1 & \\
\hline & PS 1 & $1.38(1.02-1.85)$ & .0395 \\
\hline Maximum tumor diameter $(\mathrm{cm})$ & By $1 \mathrm{~cm}$ increase & $1.12(1.02-1.22)$ & .0159 \\
\hline \multirow[t]{3}{*}{ Clinical T classification } & $\mathrm{cT} 1$ & 1 & \\
\hline & $\mathrm{cT} 2$ & $0.96(0.67-1.38)$ & .8392 \\
\hline & cT3/4 & $1.29(0.73-2.23)$ & .3804 \\
\hline \multirow[t]{3}{*}{ Clinical N classification } & cNO & 1 & \\
\hline & $\mathrm{cN} 1$ & $0.94(0.64-1.36)$ & .7608 \\
\hline & $\mathrm{cN} 2 / 3$ & $1.00(0.74-1.34)$ & .9929 \\
\hline \multirow[t]{2}{*}{ Types of resection } & Lobectomy* & 1 & \\
\hline & Pneumonectomy & $1.47(0.93-2.23)$ & .0950 \\
\hline \multirow[t]{3}{*}{ Pathologic T classification } & $\mathrm{pT} 1$ & 1 & \\
\hline & pT2 & $1.36(0.95-1.94)$ & .0954 \\
\hline & pT3 & $2.09(1.22-3.51)$ & .0075 \\
\hline \multirow[t]{3}{*}{ Adjuvant chemotherapy } & None & 1 & \\
\hline & Intravenous chemotherapy & $0.79(0.61-1.03)$ & .0821 \\
\hline & Oral tegafur and uracil & $0.80(0.56-1.13)$ & .2153 \\
\hline \multirow[t]{2}{*}{ Single or multiple N2 metastases } & Single & 1 & \\
\hline & Multiple & $1.21(0.94-1.56)$ & .1335 \\
\hline \multirow[t]{2}{*}{ Extent of N2 metastasis } & Localized & 1 & \\
\hline & Extended & $1.40(1.06-1.84)$ & .0184 \\
\hline Factors for disease-free survival & Variables & Hazard ratio $(95 \%$ CI $)$ & $P$ value \\
\hline Maximum tumor diameter $(\mathrm{cm})$ & By 1-cm increase & $1.05(0.96-1.14)$ & .3037 \\
\hline \multirow[t]{3}{*}{ Clinical T classification } & $\mathrm{cT} 1$ & 1 & \\
\hline & $\mathrm{cT} 2$ & $0.95(0.71-1.28)$ & .7564 \\
\hline & cT3/4 & $1.14(0.69-1.85)$ & .6024 \\
\hline \multirow[t]{2}{*}{ Types of resection } & Lobectomy* & 1 & \\
\hline & Pneumonectomy & $1.40(0.92-2.05)$ & .1144 \\
\hline \multirow[t]{3}{*}{ Pathologic T classification } & pT1 & 1 & \\
\hline & $\mathrm{pT} 2$ & $1.30(0.96-1.76)$ & .0927 \\
\hline & pT3 & $2.02(1.26-3.16)$ & .0038 \\
\hline \multirow[t]{3}{*}{ Adjuvant chemotherapy } & None & 1 & \\
\hline & Intravenous chemotherapy & $0.80(0.64-1.01)$ & .0588 \\
\hline & Oral tegafur and uracil & $1.02(0.75-1.36)$ & .9211 \\
\hline \multirow[t]{2}{*}{ Single or multiple N2 metastases } & Single & 1 & \\
\hline & Multiple & $1.37(1.10-1.71)$ & .0049 \\
\hline \multirow[t]{2}{*}{ Skip N2 metastasis } & Skip & 1 & \\
\hline & Nonskip & $1.31(1.06-1.62)$ & .0109 \\
\hline \multirow[t]{2}{*}{ Extent of N2 metastasis } & Localized & 1 & \\
\hline & Extended & $1.14(0.89-1.46)$ & .2878 \\
\hline
\end{tabular}

$O S$, Overall survival; DFS, disease-free survival; $C I$, confidence interval; ECOG, Eastern Cooperative Oncology Group; $P S$, performance status. *Lobectomy included lobectomy, bilobectomy, and lobectomy with bronchoplasty.

Extent of N2 metastasis was also revealed to be an independent prognostic factor affecting OS in our study. Okada and associates ${ }^{16}$ reported that survival was prolonged in patients in whom mediastinal lymph node metastasis was limited to the upper mediastinal nodes from upper lobe tumors or to lower mediastinal nodes from lower lobe tumors.
Uehara and colleagues ${ }^{17}$ also reported that metastasis to upper mediastinal lymph nodes from lower lobe tumors was indicative of a poor prognosis. These reports imply that patients with localized N2 metastasis as defined in our study had better OS than did those with extended N2 metastasis. In patients with extended N2 metastasis, tumor cells 
metastasize to lymph nodes far from the original tumor and/ or through atypical lymphatic drainage routes; thus, the cancer cells may have strong metastatic potential leading to a poor prognosis. Our findings also showed that single N2 metastasis and skip N2 metastasis are better independent prognostic factors for DFS. The finding of better DFS in patients with single N2 metastasis corroborated previous studies that reported that the number of N2 stations with metastasis was a good indicator for prognosis of completely resected N2 NSCLC. ${ }^{5,18-22}$ Involvement of multiple N2 stations implies increased tumor burden in the lymphatic flow and opportunity of systemic spread of tumor cells, which can lead to early recurrence of tumors. Skip N2 metastasis is discontinuous spread of tumors to mediastinal lymph nodes without involvement of the hilar lymph nodes. The incidence of lymph node skipping has been reported to be approximately $30 \%$ $(22 \%-50 \%),{ }^{5,6,15,17-21,23}$ and that of our study $(50.0 \%)$ was slightly higher than these previous reports, which was likely due to a bias resulting from the fact that $60 \%$ of our patients had cN0 tumors. Several studies have reported that patients with skip N2 metastasis showed better prognosis than those with nonskip N2 metastasis ${ }^{5,6,15,19}$; however, other reports with contradictory findings also exist. $^{20,21}$ In tumors with skip N2 metastasis, the total number of lymph nodes involved in tumor metastasis to both $\mathrm{N} 1$ and $\mathrm{N} 2$ stations is usually less than in those with nonskip N2 metastasis. Therefore, inasmuch as the total tumor burden in the lymphatic flow in skip N2 metastasis is presumed to be smaller than in nonskip N2 metastasis, this may lead to better DFS. ${ }^{22}$ In patients with skip N2 metastasis and who received adjuvant IV-CT, better DFS was observed, although DFS with regard to adjuvant chemotherapy was not affected by single or multiple $\mathrm{N} 2$ metastases and extent of $\mathrm{N} 2$ metastasis. The effect of adjuvant chemotherapy on the basis of pattern of metastasis to N2 regions remains unclear. Our data indicate that adjuvant IV-CT may be more effective in patients with smaller tumor burden in the lymphatic flow. In clinical trials of adjuvant chemotherapy for N2 NSCLC, pattern of metastasis to N2 regions should be taken into consideration as part of the stratification criteria of patients for further investigation.

Sex and ECOG PS were demonstrated to be independent prognostic factors for OS, but not for DFS. Female patients may gain more benefit from treatment with tyrosine kinase inhibitors for EGFR because many adenocarcinomas in female nonsmoker patients harbor EGFR gene mutations. ${ }^{12-14}$ Further, patients with PS 0 can receive more intensive and long-lasting chemotherapy than those with PS 1 after recurrence. Clearly, these endogenous factors have a great influence on OS. However, tumor recurrence depends strongly on biological features of the tumor itself and is largely independent of patient-specific factors such as age, sex, or PS.
In our report, 123 patients were clinically classified as having $\mathrm{N} 2$ or $\mathrm{N} 3(\mathrm{cN} 2 / 3)$ disease and were diagnosed with pN2 NSCLC. This subset of patients had a 5-year OS of $36.6 \%$ with surgery alone $(n=58 ; 5$-year OS, $31.8 \%$ ) or with surgery and adjuvant chemotherapy $(\mathrm{n}=65 ; 5$-year OS, 40.8\%) and are currently considered ideal for induction chemoradiotherapy followed by surgery in the clinical trial setting. ${ }^{24}$ Because patients who were not suitable for initial complete resection might have been excluded in the study, a simple comparison between our results on $\mathrm{cN} 2 / \mathrm{pN} 2$ patients and trials on induction chemoradiotherapy would not be valid. However, in some trials on induction chemoradiotherapy followed by surgery, the lung cancer was considered to be potentially technically re$\operatorname{sectable}^{25}$; thus, findings from future clinical trials on induction chemoradiotherapy followed by surgery for pathologically proven $\mathrm{cN} 2$ stage IIIA NSCLC can be noted and compared with our OS results for validation.

This study has several limitations owing to the retrospective aspect of the research. Tumors of enrolled patients were evaluated as resectable without induction treatment, which may represent a bias toward good prognosis. Survival benefit of adjuvant chemotherapy or chemoradiotherapy and detailed evaluation of treatment effects of adjuvant chemotherapy on the basis of selected regimens and of postoperative radiation therapy could not be performed because of differences in treatment protocols at each individual institution and a selection bias in which adjuvant therapy may be applied to patients with more advanced NSCLC. Therefore, our result could not conclude whether adjuvant therapy was effective in the Japanese cohort. Well-designed trials on adjuvant chemotherapy or chemoradiotherapy for completely resected stage IIIA NSCLC should be carried out to establish the significance of adjuvant therapy in the Japanese cohort.

In conclusion, our study showed that single or multiple $\mathrm{N} 2$ metastases, skip or nonskip N2 metastasis, and pT classification were independent prognostic factors for DFS, whereas extent of $\mathrm{N} 2$ metastasis, pT classification, tumor diameter, ECOG PS, and sex were significant prognostic indicators for OS in patients with completely resected $\mathrm{pN} 2$ stage IIIA NSCLC. Because the survival benefit of adjuvant chemotherapy or chemoradiotherapy remains unclear, welldesigned trials on adjuvant therapy for completely resected stage IIIA NSCLC should be carried out in the Japanese cohort, and aforementioned factors, especially pattern of metastasis to $\mathrm{N} 2$ regions, should be considered as stratification factors in these trials.

We thank all of the patients who participated in the present study and also all the surgeons who collaborated with us in the data collection and evaluation. The participating institutes included the following: Ako City Hospital (Dr Tetsuhiro Shiota); Hyogo Prefectural Amagasaki Hospital (Dr Kazumi Itoi); 
Japanese Red Cross Society, Wakayama Medical Center (Dr Shinichi Sumitomo); Kagawa University Hospital (Dr Hiroyasu Yokomise); Kansai Electric Power Hospital (Dr Hiroshi Mizuno), Kishiwada City Hospital (Dr Masahiro Kawashima); Kitano Hospital (Dr Toshihiko Taki); Kobe City Medical Center General Hospital (Dr Yutaka Takahashi); Kurashiki Central Hospital (Dr Norihito Okumura); Kyoto University Hospital (Dr Hiroshi Date); Matsue Red Cross Hospital (Dr Noritaka Isowa); Nagahama City Hospital (Dr Yasuji Terada); Nagoya Memorial Hospital (Dr Masaaki Sano); National Hospital Organization Himeji Medical Center (Dr Yoshihiro Miyamoto); National Hospital Organization Kinki-Chuo Chest Medical Center (Dr Akihide Matsumura); National Hospital Organization Kyushu Medical Center (Dr Sadanori Takeo); National Hospital Organization Nagara Medical Center (Dr Toru Tanaka); Nishi-Kobe Medical Center (Dr Minoru Aoki); Osaka Saiseikai Noe Hospital (Dr Masayoshi Teramachi); Osaka Red Cross Hospital (Dr Masaharu Nakade); Shiga Medical Center for Adults (Dr Kenzo Kawakami); Shimada Municipal Hospital (Dr Yoshimitsu Takashima); Shimane Prefectural Central Hospital (Dr Shinji Kosaka); Takatsuki Red Cross Hospital (Dr Wataru Chiba); and Tenri Hospital (Dr Tatuo Nakagawa).

\section{References}

1. Sakata R, Fujii Y, Kuwano H. Thoracic and cardiovascular surgery in Japan during 2009. Annual report by The Japanese Association for Thoracic Surgery. Gen Thorac Cardiovasc Surg. 2011;59:636-67.

2. Pignon JP, Tribodet H, Scagliotti GV, Douillard JY, Shepherd FA, Stephens RJ, et al. Lung adjuvant cisplatin evaluation: a pooled analysis by the LACE Collaborative Group. J Clin Oncol. 2008;26:3552-9.

3. Wada H, Hitomi S, Teramatsu T. Adjuvant chemotherapy after complete resection in non-small-cell lung cancer. West Japan Study Group for Lung Cancer Surgery. J Clin Oncol. 1996;14:1048-54.

4. Tada H, Tsuchiya R, Ichinose Y, Koike T, Nishizawa N, Nagai K, et al. A randomized trial comparing adjuvant chemotherapy versus surgery alone for completely resected pN2 non-small cell lung cancer (JCOG 9304). Lung Cancer. 2004;43:167-73.

5. Ichinose Y, Kato H, Koike T, Tsuchiya R, Fujisawa T, Shimizu N, et al. Overall survival and local recurrence of 406 completely resected stage IIIa-N2 non-small cell lung cancer patients: questionnaire survey of the Japan Clinical Oncology Group to plan for clinical trials. Lung Cancer. 2001;34:29-36.

6. Nakagiri T, Sawabata N, Funaki S, Inoue M, Kadota Y, Shintani Y, et al. Validation of pN2 sub-classifications in patients with pathological stage IIIA N2 nonsmall cell lung cancer. Interact Cardiovasc Thorac Surg. 2011;12:733-8.

7. Yokoi K. Record for lung cancer surgery. Kanehara shuppan. In: The Japan Lung Cancer Society, editors. General rule for clinical and pathological record of lung cancer. 7th ed.; 2010; pp. 47-61.

8. Mountain CF. Revisions in the international system for staging lung cancer. Chest. 1997; 111:1710-7.

9. Colby TV, Noguchi M, Henshke C, Vazquez MF, Geisinger K, Yokose T, et al. Adenocarcinoma. In: Travis WD, Brambilla E, Muller-Hermelink HK, Harris CC, editors. World Health Organization classification of tumours: pathology and genetics of tumours of the lung, pleura, thymus and heart. Lyon: IARC Press; 2004: $35-44$.
10. Goldstraw P, Crowley J, Chansky K, Giroux DJ, Groome PA, Rami-Porta R, et al. International Association for the Study of Lung Cancer International Staging Committee; Participating Institutions. The IASLC Lung Cancer Staging Project: proposals for the revision of the TNM stage groupings in the forthcoming (seventh) edition of the TNM Classification of malignant tumours. J Thorac Oncol. 2007;8:706-14.

11. Non-Small Cell Lung Cancer Collaborative Group. Chemotherapy and supportive care versus supportive care alone for advanced non-small cell lung cancer. Cochrane Database Syst Rev. 2010;12:CD007309.

12. Kosaka T, Yatabe Y, Endoh H, Kuwano H, Takahashi T, Mitsudomi T. Mutations of the epidermal growth factor receptor gene in lung cancer: biological and clinical implications. Cancer Res. 2004;64:8919-23.

13. Shigematsu H, Lin L, Takahashi T, Nomura M, Suzuki M, Wistuba II, et al. Clinical and biological features associated with epidermal growth factor receptor gene mutations in lung cancers. J Natl Cancer Inst. 2005;97:339-46.

14. Sonobe M, Kobayashi M, Ishikawa M, Kikuchi R, Nakayama E, Takahashi T, et al. Impact of KRAS and EGFR Gene Mutations on Recurrence and Survival in Patients with Surgically Resected Lung Adenocarcinomas. Ann Surg Oncol. 2012;19(Suppl 3):S347-54.

15. Ohta Y, Shimizu Y, Minato H, Matsumoto I, Oda M, Watanabe G. Results of initial operations in non-small cell lung cancer patients with single-level N2 disease. Ann Thorac Surg. 2006;81:427-33.

16. Okada M, Tsubota N, Yoshimura M, Miyamoto Y, Matsuoka H. Prognosis of completely resected pN2 non-small cell lung carcinomas: what is the significant node that affects survival? J Thorac Cardiovasc Surg. 1999;118:270-5.

17. Uehara H, Sakao Y, Mun M, Nakagawa K, Nishio M, Ishikawa Y, et al. Prognostic value and significance of subcarinal and superior mediastinal lymph node metastasis in lower lobe tumours. Eur J Cardiothorac Surg. 2010;38: 498-502.

18. Inoue M, Sawabata N, Takeda S, Ohta M, Ohno Y, Maeda H. Results of surgical intervention for p-stage IIIA (N2) non-small cell lung cancer: acceptable prognosis predicted by complete resection in patients with single N2 disease with primary tumor in the upper lobe. J Thorac Cardiovasc Surg. 2004;127: 1100-6.

19. Riquet M, Assouad J, Bagan P, Foucault C, Le Pimpec Barthes F, Dujon A, et al. Skip mediastinal lymph node metastasis and lung cancer: a particular N2 subgroup with a better prognosis. Ann Thorac Surg. 2005;79:225-33.

20. Lee JG, Lee CY, Park IK, Kim DJ, Cho SH, Kim KD, et al. The prognostic significance of multiple station N2 in patients with surgically resected stage IIIA N2 non-small cell lung cancer. J Korean Med Sci. 2008;23: 604-8.

21. Misthos P, Sepsas E, Kokotsakis J, Skottis I, Lioulias A. The significance of onestation N2 disease in the prognosis of patients with non-small-cell lung cancer. Ann Thorac Surg. 2008;86:1626-31.

22. Wei S, Asamura H, Kawachi R, Sakurai H, Watanabe S. Which is the better prognostic factor for resected non-small cell lung cancer: the number of metastatic lymph nodes or the currently used nodal stage classification? J Thorac Oncol. 2011;6:310-8.

23. Friedel G, Steger V, Kyriss T, Zoller J, Toomes H. Prognosis in N2 NSCLC. Lung Cancer. 2004;45:545-53.

24. van Meerbeeck JP, Kramer GW, Van Schil PE, Legrand C, Smit EF, Schramel F, et al., European Organisation for Research and Treatment of Cancer-Lung Cancer Group. Randomized controlled trial of resection versus radiotherapy after induction chemotherapy in stage IIIA-N2 non-small-cell lung cancer. $J$ Natl Cancer Inst. 2007;99:442-50.

25. Albain KS, Swann RS, Rusch VW, Turrisi AT 3rd, Shepherd FA, Smith C, et al Radiotherapy plus chemotherapy with or without surgical resection for stage III non-small-cell lung cancer: a phase III randomised controlled trial. Lancet. 2009; $374: 379-86$ 